\title{
Heat transfer vs environmental impact of modern façade systems
}

\author{
Adrian Ciutina ${ }^{1, *}$, Raluca Buzatu $^{2}$, Daniel M. Muntean ${ }^{3}$, and Viorel Ungureanu ${ }^{2}$ \\ ${ }^{1}$ CCTFC Department, Politehnica University Timisoara, 300224 Timisoara, Romania \\ ${ }^{2}$ ICER Institute, Politehnica University Timisoara, 300774 Timisoara, Romania \\ ${ }^{3}$ CMMC Department, Politehnica University Timisoara, 300224 Timisoara, Romania
}

\begin{abstract}
The paper makes an in-sight analysis of four actual steel-intensive envelope solutions existing on the market adaptable to steel structural systems. The solutions enable flexible modular construction, fast fabrication and erection times and easy disassembling. The analyses consider the heat transfer analysis including phase shift, amplitude attenuation and temperature amplitude ratio and the energy balance analysis. Considering the sustainability approach, the study is completed by an environmental impact analysis on Life-Cycle, by considering the production and end-of life stages. Although the selected systems from similar thermal resistances, the results show a certain variation of analysed parameters such as amplitude attenuation and temperature amplitude ratio (TAV). The energy balance analysis shows that the heating, solar gain and hot water preparation are responsible for the supplied energy. The emitted house energy break-down is almost equally shared among transmission, ventilation and sewage energies. The Life-Cycle Assessment (LCA) analysis proves that the end-of-life of the systems play an important role in the environmental impact of analysed systems, reversing the initial ranking of systems.
\end{abstract}

\section{Introduction}

As proven by several studies [1-3], the building sector of today is responsible for an important share of the global energy as well as total emissions and wastes, the percent raising up to 40 to $50 \%$ of the total amounts. In the traditional building system, more than $90 \%$ of the building represents the operational energy, while the rest represents the embedded energy in materials. In this logic, the actual tendency is to change this ratio by minimising the operational energy although slightly incrementing the embedded energy.

The envelope system of a building covers the entire surface of the building and is a complex matrix formed by wall, door and window openings, roofing systems. Each of these systems should possess different characteristics, in accordance to modern requirements requested by norms, in order to offer an adequate interior comfort. However, the norm requirements represent minimum requisites, higher level of internal comfort being achieved by additional systems of optimising the use of energy.

Considering the sustainable building concept [4], steel thin-walled cold-formed structures represent a very attractive structural system, as this combines the prefabrication, lightness, fast erection and reuse or recycling [5]. Steel façade systems follow the actual tendencies in construction offering robust and sustainable solutions, able to answer to actual conditions and to offer adequate interior thermal comfort.
The modern sandwich panels offered by the actual façade systems producers combines the required thermal resistance by varying the thermal insulation material and its thickness with the required structural demands. In addition, the façade layer could be over-coated with different materials, thus offering the required architectural aspect. Other advantages of the systems rely on industrialised prefabrication, fast installation and adaptability. They also could be easily disassembled. The study presents an analysis of four envelope solutions existing on the market adaptable to a thin-walled coldformed steel structural systems. The systems are chosen to offer a similar thermal resistance. The heat analyses consider the heat transfer analysis and the energy balance. The study is completed by a life-cycle environmental analysis considering the production and the end-of-life stages.

\section{Description of façade systems}

For this analysis four façade systems have been considered, proposed by different companies on the market. The choice of the systems relied on two important features: (i) modularity and (ii) ease of installation. The systems were divided in two categories depending on thermal insulating material process. The façade systems are presented in Table 1 in function of their stratification and thicknesses, resulted thermal resistance (R) or the thermal transmittance (U-value) $(\mathrm{R}=1 / \mathrm{U})$.

\footnotetext{
* Corresponding author: adrian.ciutina@upt.ro
} 
Table 1. Façade layer configurations.

\begin{tabular}{|c|c|c|c|c|c|c|}
\hline Façade system & $\begin{array}{c}\begin{array}{c}\text { Layer configuration } \\
\text { (inside - outside) }\end{array} \\
\end{array}$ & $\begin{array}{c}\mathbf{d} \\
{[\mathrm{mm}]}\end{array}$ & $\begin{array}{c}\mathbf{R} \\
{\left[\mathbf{m}^{2} \mathbf{K} / \mathbf{W}\right]}\end{array}$ & $\begin{array}{c}\mathbf{U} \\
{\left[\mathbf{W} /\left(\mathbf{m}^{2} \mathbf{K}\right)\right]}\end{array}$ & & \\
\hline \multirow{5}{*}{ Mineral wool 1 (MW1) } & 1. Steel profiles C120 - support & 120 & \multirow{5}{*}{5.943} & \multirow{5}{*}{0.168} & \multirow{5}{*}{\multicolumn{2}{|c|}{ 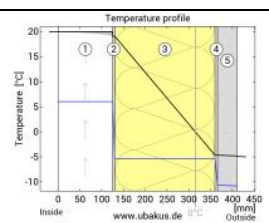 }} \\
\hline & 2. Inner Hot-dip galvanized steel sheet & 0.6 & & & & \\
\hline & 3. Mineral wool & 232 & & & & \\
\hline & 4. Polyurethane adhesive & - & & & & \\
\hline & 5. Outer Hot-dip galvanized steel sheet & 0.6 & & & & \\
\hline \multirow{4}{*}{ Mineral wool 2 (MW2) } & 1. Steel profiles C120-support & & \multirow{4}{*}{6.193} & \multirow{4}{*}{0.161} & \multirow{4}{*}{\multicolumn{2}{|c|}{ 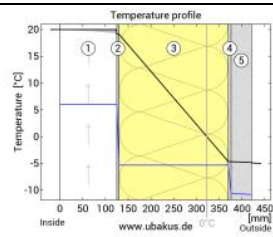 }} \\
\hline & $\begin{array}{l}\text { 2. Internal steel sheet - G, g, s, v, v2, m2 } \\
\text { - profile (galvanized and painted) }\end{array}$ & 0.5 & & & & \\
\hline & 3. Mineral wool & 240 & & & & \\
\hline & $\begin{array}{l}\text { 4. Outer steel sheet - G (smooth) - } \\
\text { profile (galvanized and painted) }\end{array}$ & 0.7 & & & & \\
\hline \multirow{4}{*}{$\begin{array}{l}\text { Polyisocyanurate } \\
\text { insulation } 1 \text { (PIR1) }\end{array}$} & 1. Steel profiles C120 - support & 120 & \multirow{4}{*}{5.850} & \multirow{4}{*}{0.171} & \multirow{4}{*}{\multicolumn{2}{|c|}{ 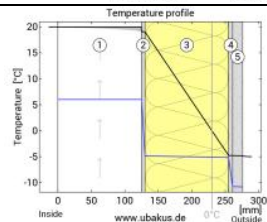 }} \\
\hline & 2. Inner ribbed steel sheet profile & 0.5 & & & & \\
\hline & 3. Polyisocyanurate (PIR) insulation & 125 & & & & \\
\hline & 4. Outer ribbed steel sheet profile & 0.6 & & & & \\
\hline \multirow{4}{*}{$\begin{array}{l}\text { Polyisocyanurate } \\
\text { insulation } 2 \text { (PIR2) }\end{array}$} & 1. Steel profiles C120-support & & \multirow{4}{*}{6.001} & \multirow{4}{*}{0.167} & \multirow{4}{*}{\multicolumn{2}{|c|}{ 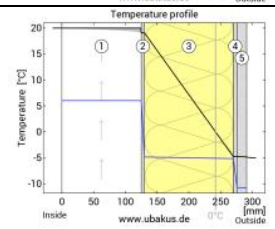 }} \\
\hline & 2. Inner precoated steel sheet & 0.5 & & & & \\
\hline & 3. Polyisocyanurate (PIR) insulation & 140 & & & & \\
\hline & 4. Outer precoated steel sheet & 0.6 & & & & \\
\hline
\end{tabular}

All proposed systems are sandwich panels, easily adapted to a steel structure made of thin-walled coldformed structural members. The choice of such integrated systems contributes to modern buildings based on sustainable characteristics both in the fabrication and in End-Of Life (EOL) stages:

- system modularity;

- adaptability to different building systems;

- prefabrication of both structure and envelope systems;

- rapid building erection;

- ease of dismantling and selection of wastes in EOL;

- reuse and recycle of materials.

Thus, the system allows the total dismantling of original components with different EOL scenarios: while the structural steel elements could be easily recycled and even reused, the final scenario for the envelope systems is more complex, as the steel sheeting and. IN consequence, the further study is focused on the performance analysis of heat transfer and environmental impact of the envelope systems.

\section{Heat transfer analysis}

The building model (Fig 1-3) represents a base unit of $5 \times 5 \mathrm{~m}$, representing a two-floor open space, with pitched roof at the second floor able to benefit and use the sun for both natural light and PV panels. The south façade (Fig. 1) is a glass curtain, offering lightning on the firstfloor, but shaded by external photo-voltaic shading lamellae. Also, the angle and the orientation of the pitched angle allows the disposition of the solar PV panels on the roof.

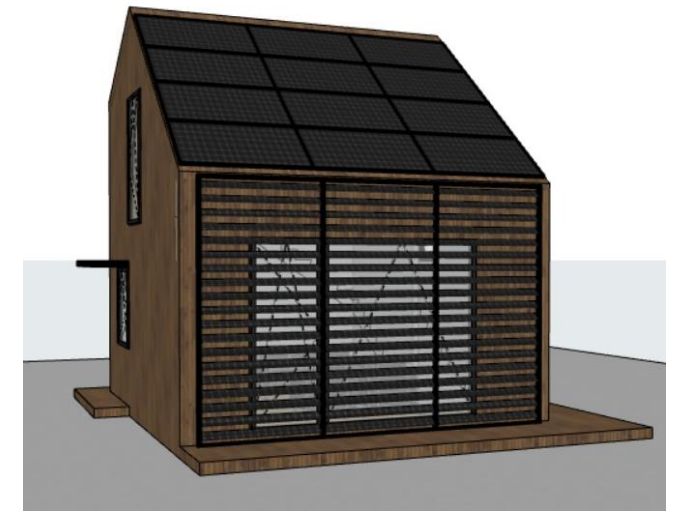

Fig. 1. 3D model preview

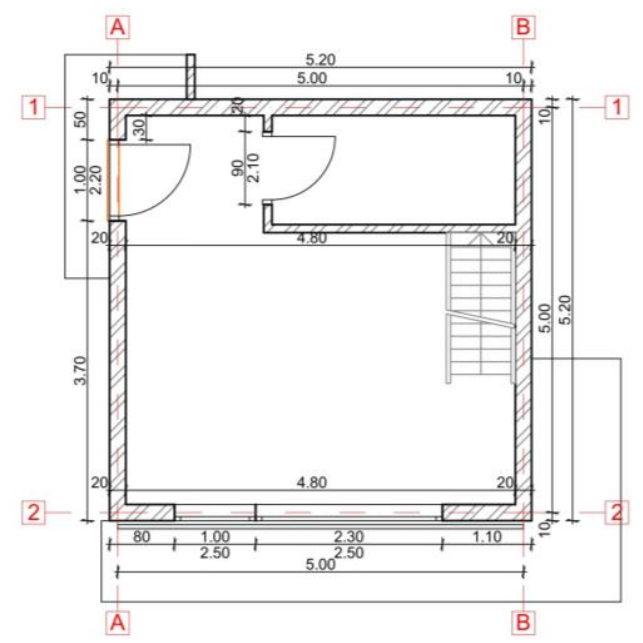

Fig. 2. Model plan

\footnotetext{
* Corresponding author: adrian.ciutina@upt.ro
} 


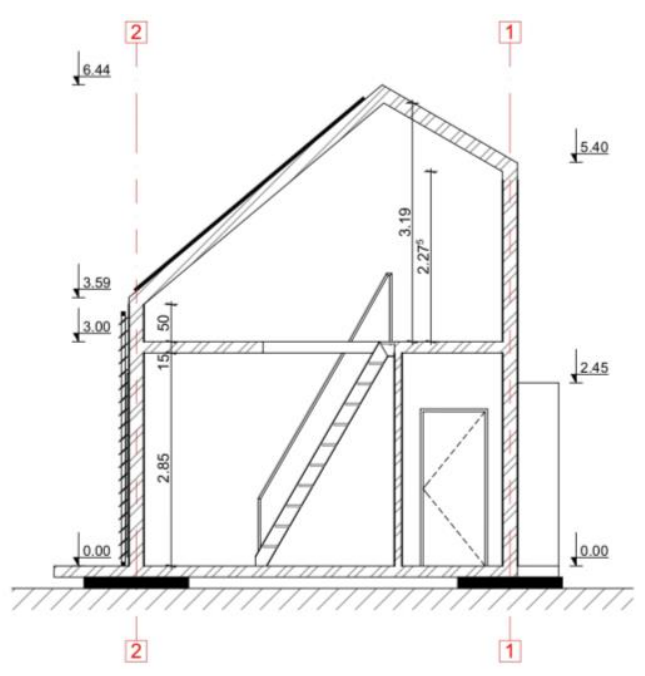

Fig. 3. Model section

The heat protection of a room is influenced by several factors, but essentially by the direct solar radiation through windows and the total amount of heat storage capacity of the elements. Other factors involved in the energy balance proved to be important, such as:

- phase shift: the time after which the peak afternoon temperature reaches the interior side of the component;

- amplitude attenuation: the attenuation of the temperature wave when passing through the façade system: a value of 10 implies that the temperature on the outside varies $10 \mathrm{x}$ stronger than on the inside, e.g. outside $15-35^{\circ} \mathrm{C}$, inside $24-26^{\circ} \mathrm{C}$;

- temperature amplitude ratio (TAV): the reciprocal of the amplitude attenuation.

The thermal analysis was carried out using an online Uvalue calculator (Ubakus) [6] and Graphisoft Archicad 21 energy evaluator add-on [7]. For the simulations the following data have been considered and applied on a base model located in the city of Timisoara, Romania:

- Inside temperature: $20^{\circ} \mathrm{C}$ and $40 \%$ humidity

- Outside temperature $-5^{\circ} \mathrm{C}$ and $60 \%$ humidity

- Gross Floor Area: $30.37 \mathrm{~m}^{2}$

- Treated Floor Area: $24.60 \mathrm{~m}^{2}$

- External Envelope Area: $120.93 \mathrm{~m}^{2}$

- Ventilated Volume: $124.44 \mathrm{~m}^{3}$

- Glazing Ratio: 6\%

\subsection{Mineral wool 1 (MW1)}

In this case (MW1 - Fig. 4) the simulation proves that the thermal protection is $\mathrm{U}=0,168 \mathrm{~W} / \mathrm{m}^{2} \mathrm{~K}$. Furthermore, the heat storage capacity of the element is $47 \mathrm{~kJ} / \mathrm{m}^{2} \mathrm{~K}$ with the thermal capacity of the inner layers at $19,7 \mathrm{~kJ} /$ $\mathrm{m}^{2} \mathrm{~K}$ and the overall thermal resistance of $5,943 \mathrm{~m}^{2} \mathrm{~K} / \mathrm{W}$. This value is more than three times greater than the current values according to current Romanian norms. Phase shift (Fig.5) is achieved after 6,7 hours with an amplitude attenuation of 7,9 and TAV 0,126.

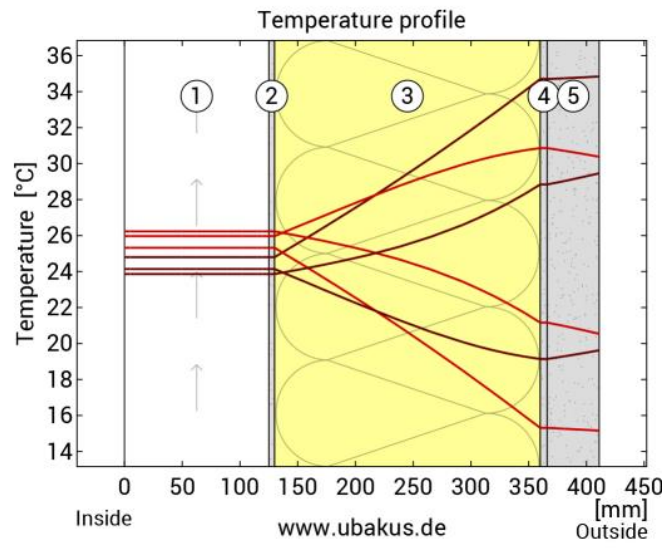

Fig. 4. Component temperature profile (dark - temperature at $3 \mathrm{pm}, 11 \mathrm{am}$ and $7 \mathrm{am}$; light - temperature at $7 \mathrm{pm}$, $11 \mathrm{pm}$ and $3 \mathrm{am})$

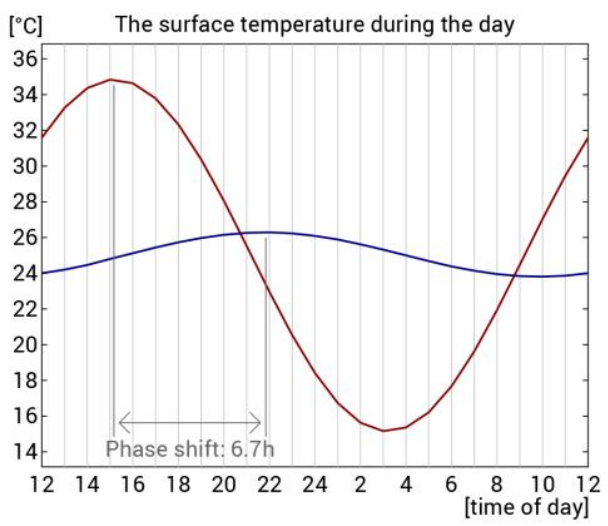

Fig. 5. Component phase shift (red-outside temperature; blue - inside temperature)

\subsection{Mineral wool 2 (MW2)}

The second system analysed MW2 (Fig. 6) proves after the simulation a thermal protection $\mathrm{U}=0,161 \mathrm{~W} / \mathrm{m}^{2} \mathrm{~K}$. The heat storage capacity of the element is $47 \mathrm{~kJ} / \mathrm{m}^{2} \mathrm{~K}$ with the thermal capacity of inner layers at $19,8 \mathrm{~kJ} / \mathrm{m}^{2} \mathrm{~K}$ and the overall thermal resistance is $6,193 \mathrm{~m}^{2} \mathrm{~K} / \mathrm{W}$. Phase shift (Fig. 7) is achieved after 6,7 hours with an amplitude attenuation of 8,3 and TAV 0,12 .

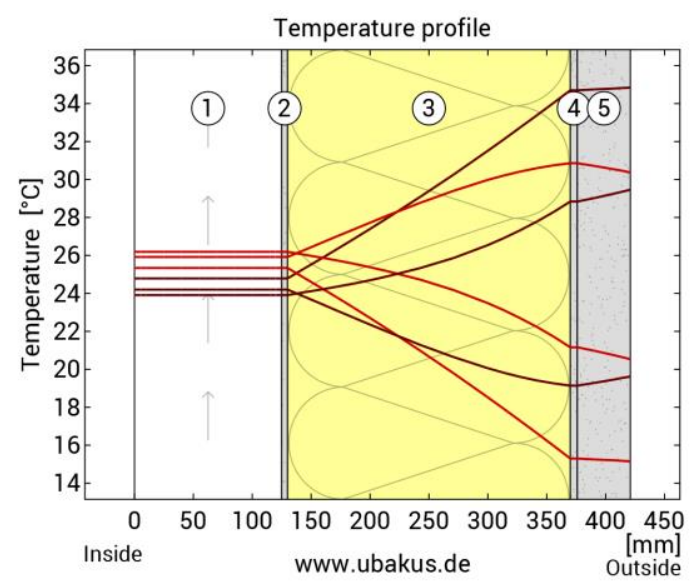

Fig. 6. Component temperature profile (dark-temperature at 3pm, 11 and $7 \mathrm{am}$; light - temperature at $7 \mathrm{pm}, 11 \mathrm{pm}$ and $3 \mathrm{am}$ ) 


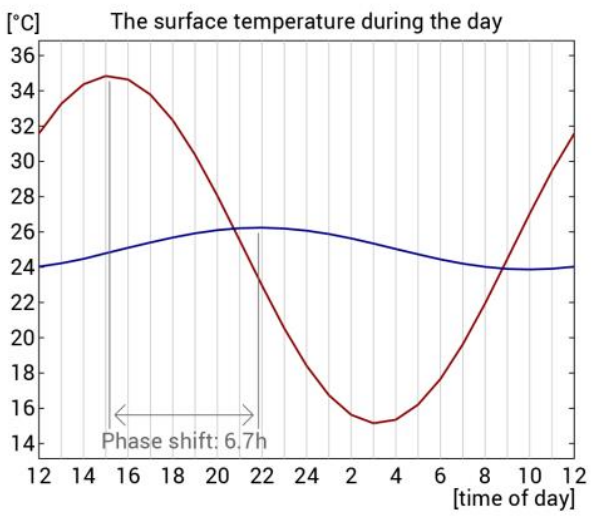

Fig. 7. Component phase shift (red-outside temperature; blue - inside temperature

\subsection{PIR insulation 1 (PIR1)}

For PIR1 system (Fig. 8), the thermal protection is $\mathrm{U}=0,171 \mathrm{~W} / \mathrm{m}^{2} \mathrm{~K}$. The heat storage capacity of the element is $46 \mathrm{~kJ} / \mathrm{m}^{2} \mathrm{~K}$ with the thermal capacity of inner layers at $21 \mathrm{~kJ} / \mathrm{m}^{2} \mathrm{~K}$ and the overall thermal resistance is $5,850 \mathrm{~m}^{2} \mathrm{~K} / \mathrm{W}$. Phase shift (Fig. 9) is achieved after 6,8 hours with an amplitude attenuation of 8,2 and TAV 0,122 . The advantage of using PIR core insulation is the overall reduced thickness of the component.

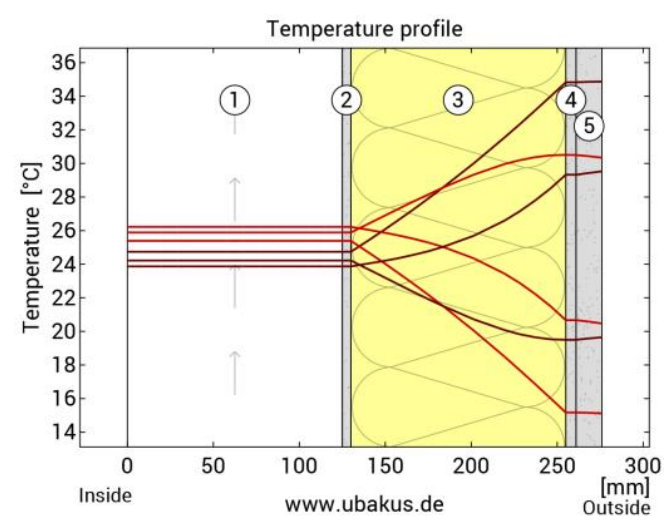

Fig. 8. Component temperature profile (dark-temperature at $3 \mathrm{pm}, 11$ and $7 \mathrm{am}$; light - temperature at $7 \mathrm{pm}, 11 \mathrm{pm}$ and $3 \mathrm{am}$ )

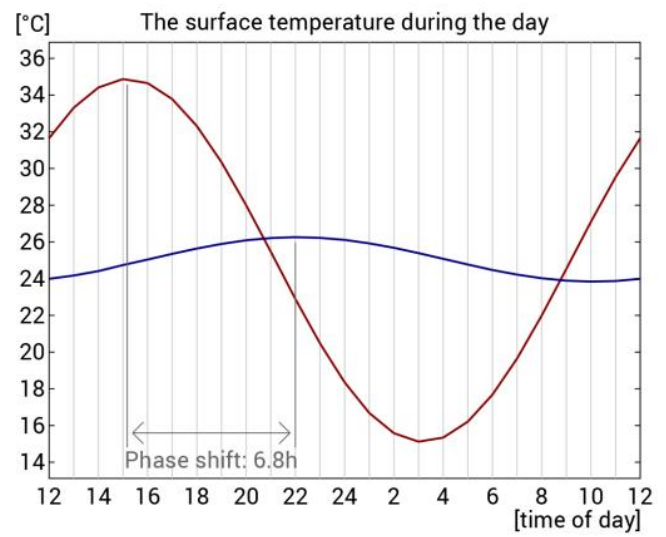

Fig. 9. Component phase shift (red-outside temperature; blue - inside temperature

\subsection{PIR insulation 2 (PIR2)}

The PIR2 system (Fig. 10), has a protection capacity $\mathrm{U}=0,167 \mathrm{~W} / \mathrm{m}^{2} \mathrm{~K}$. The heat storage capacity of the element is $46 \mathrm{~kJ} / \mathrm{m}^{2} \mathrm{~K}$ with the thermal capacity of inner layers at $21 \mathrm{~kJ} / \mathrm{m}^{2} \mathrm{~K}$ and the overall thermal resistance is $6,001 \mathrm{~m}^{2} \mathrm{~K} / \mathrm{W}$. Phase shift (Fig. 11) is achieved after 7,2 hours with and amplitude attenuation of 8,5 and TAV 0,117 .

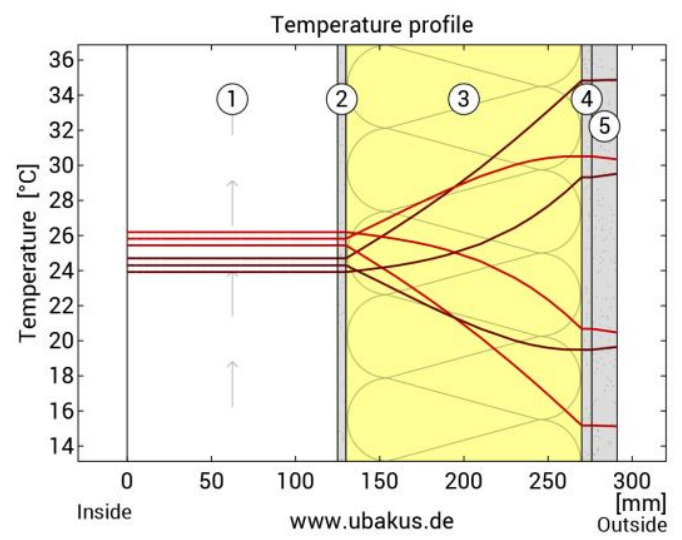

Fig. 10. Component temperature profile (dark-temperature at 3pm, 11 and 7am; light - temperature at $7 \mathrm{pm}, 11 \mathrm{pm}$ and $3 \mathrm{am}$ )

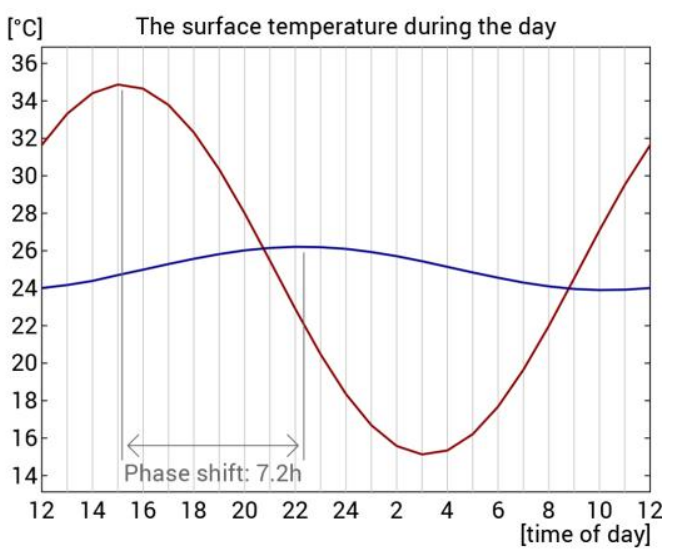

Fig. 11. Component phase shift (red-outside temperature; blue - inside temperature

\subsection{Energy balance}

In order to evaluate the energy balance of the four systems the following operation profiles have been introduced:

- human heat gain: 70W per user;

- $\quad$ service hot-water load: 601/day per user;

- humidity load: $2 \mathrm{~g} /$ day per user;

- usage rate: 6264 hours/year;

- lighting: LEDs;

- heating: $1500 \mathrm{~W}$ nominal capacity electric space heater. Service Hot-Water heating included Control type: temperature controlled with indoor sensors.

The energy-balance results are presented below in Table 2 and Table 3 . The charts show the amount of energy the building emits (bottom part), as well as the building's supplied energy: the amount of energy it absorbs from the environment and its own internal heat sources (top 
part), by month (in this case) or week, depending on the user preferences.

According to the energy balance equation, the Emitted energy and Supplied energy bars must be equal every month. The vertical axis of the chart shows an energy scale. Along the horizontal axis, the twelve months of the year are shown.

In a general overview, the supplied energy relies on heating (more than $50 \%$ of total amounts), solar gain and hot-water preparation. Other input energies are less than $7 \%$ of the total amount. The emitted building energy is based mainly in transmission - 30\%, ventilation - $45 \%$ and sewage systems $-10 \%$. These percentages indicate also the ways by which the energy balance could be optimised. In this view, heat ventilation regulators or energy sewage recovery systems can lower the overall energy balance, leading to smaller input energy amounts. It can be observed that MW2 has the lowest net heating energy balance, needing $3597 \mathrm{kWh} / \mathrm{a}$ (annually) for space heating compared to the highest, PIR2 with 3658,2 $\mathrm{kWh} / \mathrm{a}$. Besides, the mineral wool cores (MW1 and MW2) are more airtight then PIR, allowing less infiltrations and heat transmissions between the inside then the outside environments.

Table 2. Component net heating energy balance.

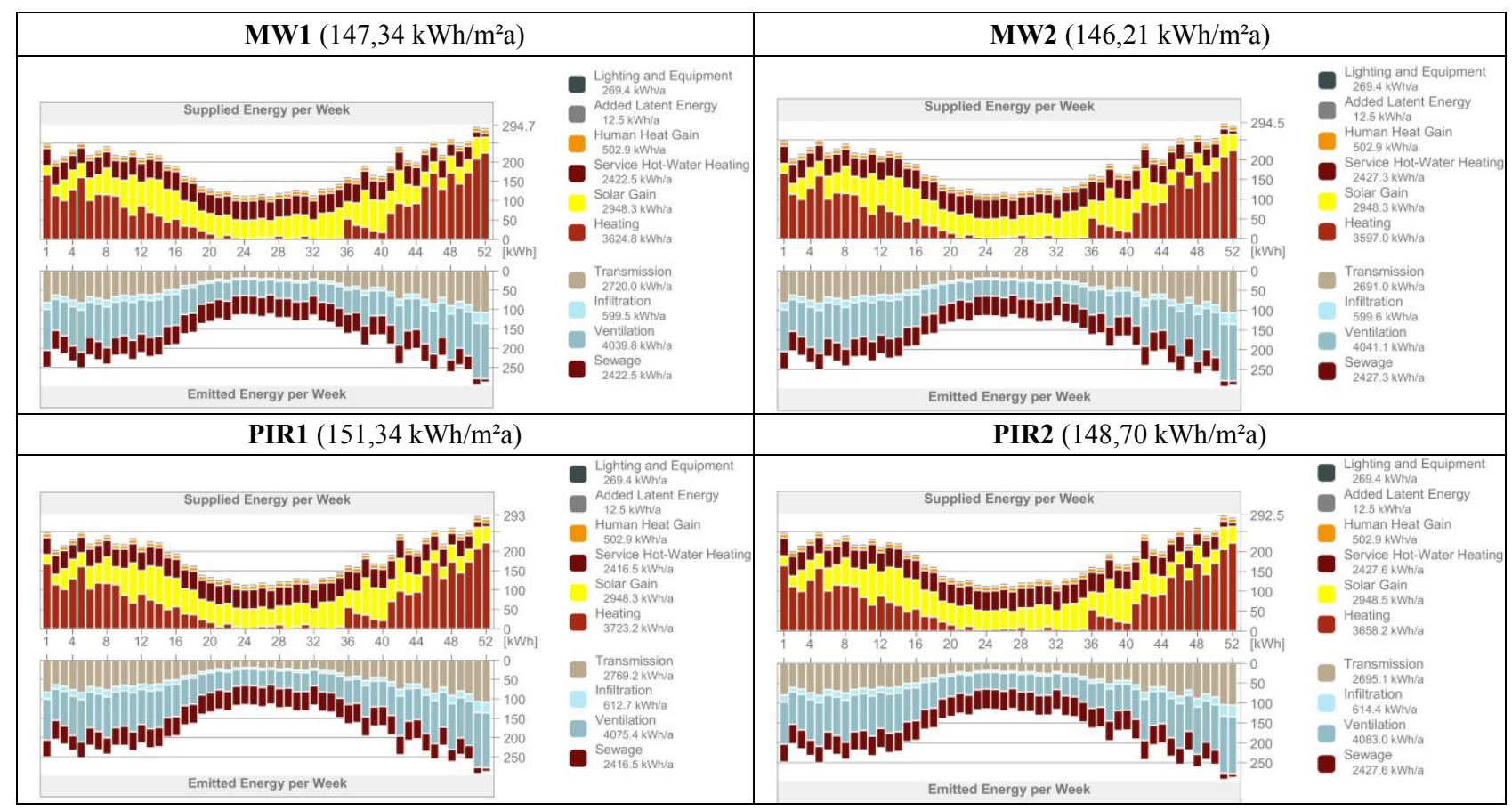

Table 3. Performance of façade systems

\begin{tabular}{|c|c|c|c|c|c|c|c|}
\hline $\begin{array}{c}\text { Facade } \\
\text { System }\end{array}$ & $\begin{array}{c}\text { Overall thermal } \\
\text { resistance } \\
{\left[\mathrm{m}^{2} \mathrm{~K} / \mathrm{W}\right]}\end{array}$ & $\begin{array}{c}\text { Lowest net heating } \\
\text { energy balance } \\
{[\mathrm{kWh} / \mathrm{a}]}\end{array}$ & $\begin{array}{c}\text { Heat storage } \\
\text { capacity } \\
{\left[\mathrm{kJ} / \mathrm{m}^{2} \mathrm{~K}\right]}\end{array}$ & $\begin{array}{c}\text { Thermal capacity } \\
\text { of inner layers } \\
{\left[\mathrm{kJ} / \mathrm{m}^{2} \mathrm{~K}\right]}\end{array}$ & $\begin{array}{c}\text { Phase } \\
\text { shift } \\
{[\text { hours }]}\end{array}$ & $\begin{array}{c}\text { Amplitude } \\
\text { attenuation }\end{array}$ & TAV \\
\hline MW 1 & 5,943 & 3624,8 & 47 & 19,7 & 6,7 & 7,9 & 0,126 \\
\hline MW 2 & 6,193 & 3597 & 47 & 19,8 & 6,7 & 8,3 & 0,120 \\
\hline PIR 1 & 5,850 & 3723,2 & 46 & 21 & 6,8 & 8,2 & 0,122 \\
\hline PIR 2 & 6,001 & 3658,2 & 46 & 21 & 7,2 & 8,5 & 0,117 \\
\hline
\end{tabular}

Table 3 synthetically presents the performances of the façade systems. The general conclusion of the study shows that all the parameters present similar values, the variation being of 5-6\% among the studied cases. The MW2 solution presenting the highest thermal resistance (smallest U-value) leads also to the net heating energy balance and the lowest TAV value. In contrast, the highest amplitude attenuation and thermal capacity of inner layers are obtained for PIR2 solution.

\section{Environmental impact analysis}

The environmental impact analysis was assessed through a Life Cycle Analysis (LCA), by considering the early stages (raw material acquisition and production), and end-of-life phase - relating recycling and final disposal.

The LCA analysis was elaborated using SimaPro [8] software program considering some system boundaries such as identical components and features:

- envelopes are made of sandwich panels with the same thermal transmittance value of $0,17 \mathrm{~W} / \mathrm{m}^{2} \mathrm{~K}$;

- exclusion of energy used for construction purposes (energy for technological machinery);

- the exclusion of the transportation and the installation on-site;

- the inclusion of long-term emissions. 
Table 4. Stratification of materials, quantities/sqm and end-of-life scenario for envelope systems

\begin{tabular}{|c|c|c|c|c|c|c|}
\hline FAC CADE SISTEM & MATERIAL & Surface [mp & D [mm] & $\mathrm{kg} / \mathrm{mp}$ & Weight [kg] & Disposal scenario \\
\hline \multirow{5}{*}{$\begin{array}{c}\text { MW } 1(23,8 \\
\mathrm{kg} / \mathrm{mp})\end{array}$} & Steel profiles $\mathrm{C} 120[\mathrm{ml}]$ & 137,34 & & 2.68 & 368.0712 & $100 \%$ Recycling \\
\hline & Inner Hot-dip galvanized steel sheet & 85,41 & 0,6 & 5,32 & 454,3812 & $90 \%$ Recycle, $10 \%$ Waste \\
\hline & Mineral wool & 85,41 & 232 & 24,52 & 2094,2532 & 70\% Recycle; $30 \%$ Waste \\
\hline & Polyurethane adhesive & 85,41 & & 0,394 & 33,65154 & $100 \%$ Waste \\
\hline & Outer Hot-dip galvanized steel sheet & 85,41 & 0,6 & 5,32 & 454,3812 & $90 \%$ Recycle, $10 \%$ Waste \\
\hline \multirow{3}{*}{$\begin{array}{c}\text { MW } 2(32,8 \\
\mathrm{kg} / \mathrm{mp})\end{array}$} & - G, g, S, v, v2, m2 - profile (galvanized and painted) & 85,41 & $.5 / .6$ & 4,433 & 378.62253 & $90 \%$ Recycle, $10 \%$ Waste \\
\hline & Mineral wool & 85,41 & 240 & 22,16 & 1892,6856 & $70 \%$ Recycle; $30 \%$ Waste \\
\hline & sheet - $\mathrm{G}$ (smooth) - profile (galvanized and painted) & 85,41 & 0,7 & 6,21 & 530,3961 & $90 \%$ Recycle, $10 \%$ Waste \\
\hline \multirow{4}{*}{ PIR $1(15,5 \mathrm{~kg} / \mathrm{mp})$} & Steel profiles C120 & & & & 368,07 & $100 \%$ Recycling \\
\hline & Inner ribbed steal sheet profile & 85,41 & 0,5 & 4,4333 & 378,648153 & $90 \%$ Recycle, $10 \%$ Waste \\
\hline & PIR insulation & 85,41 & 125 & 5,75 & 491,1075 & $90 \%$ Recycle, $10 \%$ Landfill \\
\hline & Outer ribbed steal sheet profile & 85,41 & 0,6 & 5,32 & 454,3812 & $90 \%$ Recycle, $10 \%$ Waste \\
\hline \multirow{3}{*}{$\begin{array}{c}\text { PIR } 2(15,17 \\
\mathrm{kg} / \mathrm{mp})\end{array}$} & Inner precoated steel sheet & 85,41 & 0,5 & 4,43 & 378,3663 & $90 \%$ Recycle, $10 \%$ Waste \\
\hline & PIR insulation ( type PRT - Hexacore) & 85,41 & 140 & 5,42 & 462,9222 & 90\% Recycle, $10 \%$ Landfill \\
\hline & Outer precoated steel sheet & 85,41 & 0,6 & 5,32 & 454,3812 & $90 \%$ Recycle, $10 \%$ Waste \\
\hline
\end{tabular}

The Life-Cycle scenario included as input data, the same component materials and quantities used for the heat transfer analysis. Data referring to end-of-life phase, representing the scenario for recycle, reusing and disposal of the building materials at the end-of-life of the building, was considered according to the actual conditions in Romania for disposal of envelope materials. Table 4 presents the components of each envelope solution analysed, as well as the related quantities and the disposal scenario for every layer of analysed façade system.

Figure 12 shows the environmental impact of the analysed solutions in the production stage, while Figure 13 refers to the environmental impact of the four solutions resulting from LCA analysis at the end-of-life phase, thus including the end-of-life stage. The environmental impact is expressed in eco-points as defined by the damage oriented method for LCA, Ecoindicator 99 [8] and grouped in three main categories of impact: resources (which is divided in land use, minerals and fossil fuels), ecosystem quality (divided in climate change, radiation, ozone layer, eco-toxicity and acidification/eutrophication) and human health (divided in respiratory organics, carcinogens and respiratory inorganics).

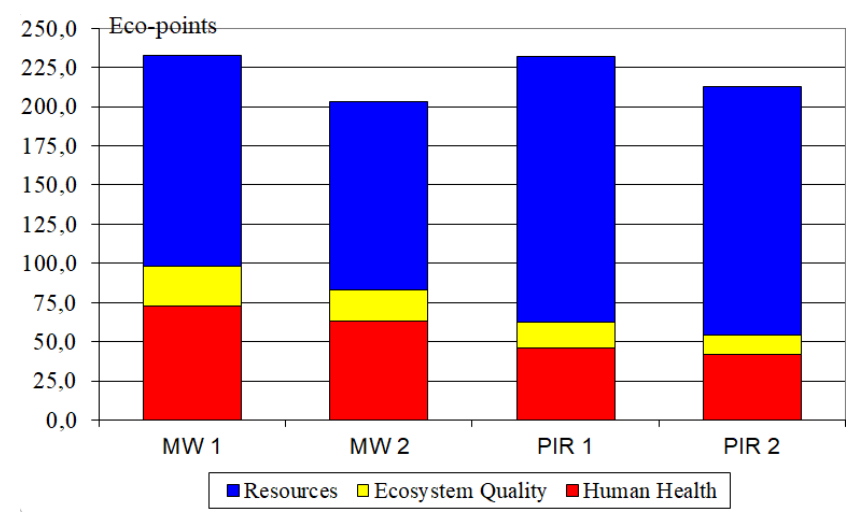

Fig. 12. Environmental impact of the facades (considering the production stage) [8]

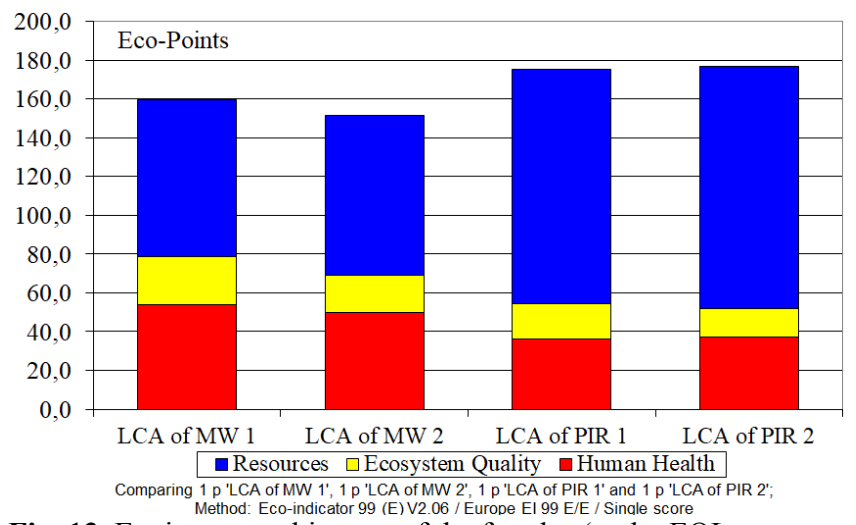

Fig. 13. Environmental impact of the facades (at the EOL stage) [8]

The global score for each envelope solution analysed is presented in the table 5 and table 6 below. The systems, with the highest scores are in fact the envelope systems bringing the most significant impact on the environment. As global results, all systems present similar total scores. The comparison of results on production stage and on the LCA show that by considering the EOL, the global scores are reduced through reuse and recycling of different materials in ratios up to $30 \%$. Moreover, the analysis on the life-cycle can reverse the ranking of solutions in global scores: the PIR1 solution show higher scores in production stage while the LCA analysis reveals equal PIR1 and PIR2 global scores.

Table 5. Environmental impact - production stage

\begin{tabular}{|c|c|c|c|c|}
\hline Facade & \multirow{2}{*}{$\begin{array}{c}\text { Environmental } \\
\text { imptem }\end{array}$} & \multicolumn{3}{|c|}{ Damage category } \\
\cline { 3 - 5 } & $\begin{array}{c}\text { impact - at the } \\
\text { end-ofife } \\
\text { stage [total } \\
\text { eco-points] }\end{array}$ & $\begin{array}{l}\text { Human } \\
\text { Health }\end{array}$ & $\begin{array}{c}\text { Ecosystem } \\
\text { Quality }\end{array}$ & Resources \\
\hline MW 1 & 232 & 72,30 & 25,47 & 134,15 \\
\hline MW 2 & 203 & 62,94 & 19,79 & 120,38 \\
\hline PIR 1 & 231 & 45,52 & 16,02 & 169,52 \\
\hline PIR 2 & 212 & 41,46 & 12,09 & 158,76 \\
\hline
\end{tabular}

\footnotetext{
* Corresponding author: adrian.ciutina@upt.ro
} 
Table 6. Environmental impact at the end-of-life stage

\begin{tabular}{|c|c|c|c|c|}
\hline \multirow{2}{*}{$\begin{array}{l}\text { Facade } \\
\text { System }\end{array}$} & \multirow{2}{*}{$\begin{array}{c}\text { Environmental } \\
\text { impact - at the } \\
\text { end-of-life } \\
\text { stage [total } \\
\text { eco-points] }\end{array}$} & \multicolumn{3}{|c|}{ Damage category } \\
\hline & & $\begin{array}{l}\text { Human } \\
\text { Health }\end{array}$ & $\begin{array}{c}\text { Ecosystem } \\
\text { Quality }\end{array}$ & Resources \\
\hline MW 1 & 160 & 53,38 & 25,64 & 81,04 \\
\hline MW 2 & 151 & 49,40 & 19,16 & 82,58 \\
\hline PIR 1 & 171 & 32,86 & 15,92 & 121,81 \\
\hline PIR 2 & 173 & 35,47 & 12,21 & 125,05 \\
\hline
\end{tabular}

As the results show, overall, all four envelope systems prove very similar scores, both in the production stage and at the end-of-life cycle. However, the system with the least impact on the environment changes from the production stage until the end-of-life of the facades due to re-use and energy recovery from the component materials of the facades. It could be observed that in the production stage, the solution with the minimum ecopoints gained is Solution no. 4, followed by Solution no. 3 while at the end-of-life cycle Solution no. 3 is ranked last with the respect to the environmental impact. Nevertheless, Solution no. 4 (based on a mineral wool insulation core) manages to keep the first position in the top of analysed systems, thus less impacting on the environment.

In terms of the damage category, all four solutions, both in the production stage and at the end-of-life stage, have to greatest impact on Resources, translating practically the high manufacturing levels of the component products by using energy.

\section{Conclusions}

The paper presents a comparative analysis of some four steel-intensive façade systems, existent on the European market and adaptable for steel structures made of coldformed thin-walled elements. The four systems were chosen on the basis of similar thermal resistance values (U-values).

Following the thermal, energy balance and environmental analysis, the following conclusions could be drawn:

- starting from similar values of thermal resistances, the four façade systems show similar values of phase shift, amplitude attenuation and temperature amplitude ratio;

- on the other hand, the emitted house energy is shared among transmission, ventilation and sewage energies. Thus, better insulation and heat exchangers can reduce the lost energy of the building;

- the energy balance break-down proves that the heating, solar gain and hot water preparation are responsible for the supplied energy. In order to reduce the conventional energy supplied, additional green energy systems could be employed;

- the results show a certain variation of the thermal analysed parameters such as amplitude attenuation and TAV. The MW2 solution shows leads to the net heating energy balance and the lowest TAV value;

- the LCA environmental analysis proves that the endof-life of the systems play an important role in the environmental impact of analysed systems, reversing the initial ranking of systems. However, this depends on the scenarios made for the end-of-life;

- the choice of the façade system used on buildings could be taken on the basis of the results of analyses, by considering both the thermal capacities of the systems and their global environmental load on the life-cycle.

This work was supported by a grant of the Romanian Ministery of Research and Innovation, CCCDI - UEFISCDI, project number PN-III-P1-1.2-PCCDI-2017-0391 / CIA_CLIM Smart buildings adaptable to the climate change effects, within PNCDI III.

\section{References}

1. CIOB, Sustainability and Construction, www.ciob.org.uk.

2. UIA 2009. Copenhagen Declaration, Declaration on Sustainability and Cultural Diversity, Approval by the UIA World Congress in June 2008, www.uiaarchitectes.org

3. European Construction Technology Platform, Vision 2030 \& Strategic Research Agenda, Focus Area Cities and Buildings (2005)

4. M.R.C. Doughty, G.P. Hammond, Sustainability and the build environment at and beyond the city scale. Building and Environment 2004 Vol. 39, 1223-1233, (2004) D. Dubina, V. Ungureanu, A. Ciutina, M. Mutiu, D. Grecea Innovative sustainable steel framing based affordable house solution for continental seismic areas proceedings of: Structures and Architecture, Guimaraes, Portugal, (21-23 July 2010), ISBN 978-0-415-49249-2

5. Ubakus - online U-wert calculator https://www.ubakus.de/u-wert-rechner/

6. Graphisoft ARCHICAD 21.0.0 build 3005, http://www.graphisoft.com/archicad/

7. SimaPro 7. Software and database manual, Amersfoort, The Netherlands (2008), online at: www.presustainability.com

8. Eco-indicator'99 2000. Eco-indicator'99 - Manual for Designers. A damage oriented method for Life Cycle Impact Assessment, online at: http://www.pre.nl/download 